\title{
Plano de negócio para a produção de húmus em sistema big bags
}

\section{Business plan for the humus production in big bags system}

\author{
Allison Marques Soares \\ Universidade Federal da Grande Dourados \\ E-mail: allisonmsoares@gmail.com \\ OrcID: https://orcid.org/0000-0002-6185-3045
}

Ariély Leite Canassa

Universidade Federal da Grande Dourados

E-mail: ariely.canassa@gmail.com

OrcID: https://orcid.org/0000-0003-0780-1778

Joyce Castro Xavier

Universidade Federal da Grande Dourados

E-mail: joyxcastro@gmail.com

OrcID: https://orcid.org/0000-0002-0993-6740

Priscila Elise Alves Vasconcelos Universidade Federal da Grande Dourados

E-mail: priscascon@gmail.com

OrcID: https://orcid.org/0000-0001-8747-9920

Carla Eloize Carducci

Universidade Federal da Grande Dourados

E-mail: carlacarducci@ufgd.edu.br

OrcID: https://orcid.org/0000-0001-5736-3775

\begin{abstract}
Resumo: Com a implantação da PNRS - Lei 12.305/10, ampliou-se a busca por soluções sustentáveis para a gestão dos resíduos sólidos orgânicos, uma das alternativas viáveis ambiental e economicamente é a vermicompostagem. Nosso objetivo foi analisar um plano de negócios para a implantação de um modelo de produção de vermicomposto em sistema de Big bags, originado de resíduos vegetais e animais. Utilizou-se Big bags com capacidade de $1.000 \mathrm{~kg}$ (bolsas de fertilizantes reutilizados). Para a produção do húmus misturouse: folhas secas $(6,25 \%)$, esterco curado $(72,13 \%)$, água $(15,62 \%)$ e minhocas (Eisenia Foetida, 6\%) provenientes da propriedade. Estes materiais foram acondicionados na Big bag, todo o processo de transformação em húmus ocorreu em 73 dias, com produção final de $320 \mathrm{~kg}$ de húmus $/ 0,542 \mathrm{~m}^{3} \mathrm{com}$ umidade de $47 \%$. O sistema foi composto por três Big bags que corresponderam a um módulo de produção, e para essa avaliação utilizou-se dois módulos, obtendo-se assim, a produção final escalonada de $320 \mathrm{~kg} / \mathrm{mês}$. Através de indicadores financeiros (ROI, TIR, VPL e Payback) foi possível obter a lucratividade de 60,68\% que equivaleu à $R \$ 667,44 /$ mês, verificou-se que o retorno do investimento inicial se conclui ao terceiro mês neste modelo de negócio, além do pró-labore de $R \$ 261,25 /$ mês equivalente a $1 / 4$ de um salário mínimo $(R \$ 1.045,00)$. Verificouse que a produção de húmus em Big bags + vermicompostagem, é viável ao produtor rural, por ser uma nova alternativa de renda e auxiliar na redução dos impactos ambientais causados pelo descarte incorreto dos resíduos orgânicos gerados em propriedades rurais.
\end{abstract}

Palavras-chave: Adubo orgânico; Reaproveitamento de resíduos orgânicos; Sustentabilidade; Bioeconomia.

Abstract: With the implementation of the NSWP (Law 12,305/10), the search for sustainable solutions for the management of organic solid waste was expanded, one of the environmentally and economically viable alternatives is vermicomposting. Our aim was to analyze a business plan for the implementation of a vermicompost production model in a Big bag system, originating from plant and animal waste. Big bag with 1,000 
$\mathrm{kg}$ of capacity were used (reused chemical fertilizers bags). For the humus production, it was mixed: dry leaves $(6.25 \%)$, tanned manure $(72.13 \%)$, water $(15.62 \%)$ and earthworms (Eisenia Foetida, $6 \%)$ from the rural property. These materials were stored in the Big bag, the entire transformation process into humus took place in 73 days, with a final production of $320 \mathrm{~kg}$ of humus $/ 0.542 \mathrm{~m}^{3}$ with a humidity of $47 \%$. The system was composed of three Big bags that corresponded to a production module, and for this evaluation two modules were used, thus obtaining the final staggered production of $320 \mathrm{~kg} / \mathrm{month}$. Through financial indicators (ROI, TIR, NPV and Payback) it was possible to obtain a return of $60,68 \%$, which was equivalent to $R \$ 667,44 /$ month, it was found that the return on the initial investment is concluded in the third month in this business model, in addition to cash of $R \$ 261,25 /$ month equivalent to $1 / 4$ of a minimum wage ( $R \$ 1,045.00)$. It was found that the production of humus in Big bags + vermicomposting is viable for rural producers, for being a new income alternative and helps to reduce environmental impacts caused by the incorrect disposal of organic waste generated in rural properties.

Key-words: Organic fertilizer; Reuse of organic waste; Sustainability; Bioeconomy.

Data de recebimento: $26 / 05 / 2020$

Data de aprovação: 08/10/2020

DOI: https://doi.org/10.30612/agrarian.v13i50.12043

\section{Introdução}

Com a publicação da Lei $n^{\circ}$ 12.305/10, que institui a Política Nacional de Resíduos Sólidos (PNRS), onde há uma abordagem acerca do descarte de resíduos e da responsabilização judicial-administrativa (BRASIL,2010), ampliou-se a busca por soluções sustentáveis para gestão dos resíduos sólidos orgânicos.

Estratégias como a compostagem e a vermicompostagem ganharam destaque para o tratamento desses resíduos. A redução do uso de espaços em aterros sanitários, a eliminação de passivos ambientais e a transformação de um resíduo em material com valor agregado passam a ser vistas como alternativas sustentáveis para reposição de nutrientes no solo, ou seja, novo adubo(DAL BOSCO et al., 2017).

Segundo as diretrizes e técnicas descritas na Política Nacional de Resíduos Sólidos (BRASIL, 2010), a compostagem e a vermicompostagem passam a ser a melhor forma de tratar esses resíduos. Esses processos melhoram as características físicas, químicas e biológicas do resíduo e, consequentemente, melhora sua aceitação e valor comercial (CONTI et al., 2014; BLOUIN et al., 2019)

A principal diferença entre a compostagem e a vermicompostagem é que; a primeira tem ação de organismos decompositores, enquanto a segunda tem como agentes de transformação as minhocas e outros micro-organismos. Estes se alimentam dos resíduos adicionados ao solo e seus excrementos têm uma variedade de nutrientes para uso na agricultura (Carbono, Nitrogênio, Potássio entre outros), que podem complementar ou até mesmo substituir algumas formulações de fertilizantes industriais (BRITO et al., 2010; LOSS et al., 2009; BRASIL, 2017).

Dentro de uma propriedade rural, grandes volumes de resíduos orgânicos são gerados (oriundos de folhas, podas, gramíneas, restos culturais e resíduos residenciais) pela atividade agropecuária e constituem matéria-prima fundamental para a reciclagem, a exemplo, dos resíduos gerados durante o ciclo de produção animal. Comumente esses tipos de resíduos são pouco explorados ou potencializados dentro da propriedade rural, sendo muitas vezes descartados e inutilizados (SOARES, 2019).

Por meio de biotecnologias por exemplo, utilizando a vermicompostagem, esses resíduos podem ser transformados em um composto orgânico de alto potencial de uso agrícola. Esse composto pode ser utilizado como fonte de nutrientes para a produção de alimentos na própria propriedade rural ou comercializado, instituindo uma nova fonte de renda ao produtor.

Com o uso constante de fertilizantes sintéticos, estes tem causado algum nível de degradação do solo, como exemplo, em cultivo de olerícolas, com a prática da fertirrigação, tem-se a preocupação com certos indicadores, como a salinização do solo, que reduz a disponibilidade de água às plantas, além de exercer efeitos tóxicos de íons específicos sobre os processos fisiológicos e metabólicos das plantas além de comprometer o rendimento e a qualidade da produção (MEDEIROS et al., 2009). Existem várias alternativas para mitigar os efeitos dos sais da água de irrigação nas plantas, como, a aplicação de resíduos orgânicos no 
solo, como o húmus da vermicompostagem, que é um sistema tecnológico de baixo custo e não poluente (SANTOS et al., 2019; BASSACO et al., 2015; SCHIEDECK et al., 2006).

As Big bags, embalagens ou contentores (ABNT NBR 16029:2012), também conhecidos como FIBC (flexible intermediate bulk container), muito utilizados na agricultura para transporte de fertilizantes industriais, são flexíveis e suportam uma carga de 2 toneladas (CONTEFLEX, 2018), por serem feitos de material de alta resistência (polipropileno) ao transporte e estocagem. Após o uso principal (transporte de fertilizantes), as Big bags podem ser reaproveitados para servir como local de armazenamento e produção de adubo orgânico, sendo dessa forma considerados de baixo custo e de fácil manuseio para produção desse material.

Além disso, as Big bags protegem as minhocas e o vermicomposto dos agentes externos. Ajuda a manter e conservar o conteúdo de água no material nele alocado, onde pequenos espaços entre os fios da malha servem como um poro promovendo a drenagem e aeração do material em decomposição. Destaca-se, também a facilidade e agilidade de uso das Big bags para a produção de adubos orgânicos, como da vermicompostagem (SOARES, 2019). Outra questão é que não há na literatura nacional, publicações ou relatos do uso dos Big bags como recipiente de produção e armazenagem de adubos orgânicos, o que o torna promissor para a produção de húmus tanto em pequena como em grande escala.

Para uma atividade agrícola ser considerada sustentável, esta deve ser economicamente viável, ambientalmente correta e socialmente justa, ou seja, a reutilização de materiais para produção de alimentos deverá atingir esses pressupostos e, consequentemente, esses refletem na produção de alimentos mais seguros (GLIESSMAN, 2000; SMYTH; DUMANSKI, 1995; SCHIEDECK et al., 2006). Portanto, é possível que uma produção especializada, mesmo que familiar, possa ter um acréscimo no valor agregado ao seu produto final (vegetais, frutas, flores e grãos comercializáveis).

Nesse contexto, este trabalho tem como objetivo analisar um plano de negócios para a implantação de um modelo de produção de húmus de minhoca por meio da vermicompostagem em sistema de Big bags, originados de resíduos vegetais e animais.

\section{Material e Métodos}

\section{Descrição da área de estudo}

O experimento foi conduzido na propriedade rural Sítio Soares, localizada no município de Dourados MS, distante $6 \mathrm{~km}$ do distrito de Indápolis, pela Rod. Aparecido de Souza Breguedo - MS-274, que tem por coordenadas geográfica 2210'45.1"S 54³7'12.9"W e altitude 394m. Entre Agosto de 2019 e Fevereiro de 2020.

Para o desenvolvimento dessa pesquisa, foi utilizada como ferramenta de avaliação a base de cálculos financeiros do software CEPN 3.0 - Como Elaborar um Plano de Negócio, disponibilizado de forma gratuita pelo Sebrae, assim como indicadores financeiros como Taxa Interna de Retorno (TIR), Valor Presente Líquido (VPL), Retorno sobre Investimento (ROI) e Prazo de retorno do investimento (Payback). Fez-se necessário também a realização de pesquisas de mercado no âmbito regional do centro-sul de Mato Grosso do Sul, especificamente o município de Dourados. O produtor de húmus de minhoca mais próximo do município objeto do estudo, está localizado em Campo Grande, capital do estado - (Tabela 01).

Tabela 01. Dados de localização, mercado e venda de húmus de minhoca em Campo Grande-MS.

\begin{tabular}{ccccccc}
\hline Empresa & Qualidade & Preço & $\begin{array}{c}\text { Condições de } \\
\text { pagamento }\end{array}$ & Localização & Atendimento & $\begin{array}{c}\text { Serviço } \\
\text { ao cliente }\end{array}$ \\
\hline $\begin{array}{ccccc}\text { Estancia } \\
\text { Chiquito }\end{array}$ & Boa/Ótima & $\mathrm{R} \$ 600,00 /$ ton. & à vista & $\begin{array}{c}\text { Campo Grande } \\
\text { MS }\end{array}$ & $\begin{array}{c}\text { Direto no local } \\
\text { ou via telefone }\end{array}$ & $\begin{array}{c}\text { Húmus de } \\
\text { minhoca }\end{array}$ \\
\hline
\end{tabular}

Fonte: Estância Chiquito, Campo Grande/MS.

\section{Descrição do Negócio}

Na produção agrícola, de modo geral, são gerados muitos resíduos (tanto da parte animal, quanto da parte vegetal). Estes resíduos podem ser reaproveitados para se tornar um potencial fertilizante pois, o material orgânico gerado é rico em nutrientes utilizados na agricultura, de forma in natura e/ou processados. 
Nesse sentido, a missão do negócio foi produzir e fornecer produto orgânico rico em nutrientes e com qualidade equivalente a insumos industriais já utilizados na agricultura, respeitando o meio ambiente e seus indivíduos (minhocas, fungos, insetos e outros organismos da fauna do solo).

Para tanto há a possibilidade de comercialização, de dois tipos de produto: o húmus de minhoca sólido e as próprias minhocas. Utilizou-se na simulação o valor de venda de $R \$ 3,00 \mathrm{~kg}^{-1}$ de húmus e $\mathrm{o}$ valor aproximando de $\mathrm{R} \$ 400,00 \mathrm{~L}^{-1}$ de minhoca vermelhas californianas (Eisenia Foetida), onde $1 \mathrm{~L}$ de minhocas contem aproximadamente 1.200 minhocas (há variação de mercado de $\mathrm{R} \$ 0,34 /$ unidade a $\mathrm{R} \$ 0,36 /$ unidade). Essas informações foram levantadas através de pesquisa de mercado realizada no município de Dourados/MS, via site MF Rural (www.mfrural.com.br) e in loco com o produtor da Estância Chiquito de Campo Grande/MS.

\section{Análise de mercado}

O público-alvo da pesquisa são os consumidores de insumos para floricultura, jardinagem, produtores de mudas de diversos tipos de plantas, principalmente as hortaliças. Esses clientes buscam esse tipo de produto por ser orgânico, ter preço mais acessível frente aos insumos industriais e gerar bons resultados. Assim como os fertilizantes sintéticos, quando utilizados na forma e quantidade correta, o adubo orgânico pode agregar valor ao produto que será comercializado e ter eficiência na reposição de nutrientes no solo.

\section{Estudo de concorrentes}

Não foi observada existência de concorrência consolidada no mercado para o município de Dourados. No entanto, a propriedade Estância Chiquito localizada no município de Campo Grande atende a região próxima à capital e, portanto, não foi considerada concorrente direto para Dourados (Tabela 01).

\section{Estudo de fornecedores}

Na Tabela 02 é apresentado o estudo de fornecedores de matéria-prima para a produção de húmus de minhoca em Big bags. Vale ressaltar que, neste trabalho, encontra-se a reutilização de Big bags que tem como principal uso o transporte e armazenamento de adubos químicos, sendo este material (resíduo) mantido nas propriedades rurais, sem plano de logística reversa até então.

Tabela 2. Relação de matérias-primas utilizadas para a produção de húmus via vermicompostagem em Big bags.

\begin{tabular}{ccccccc}
\hline Ordem & $\begin{array}{c}\text { Matéria-prima e } \\
\text { insumos }\end{array}$ & $\begin{array}{c}\text { Nome do } \\
\text { fornecedor }\end{array}$ & Preço & Pagamento & $\begin{array}{c}\text { Prazo de } \\
\text { entrega }\end{array}$ & Localização \\
\hline 1 & $\begin{array}{c}\text { Esterco bovino } \\
\text { pré-curtido }\end{array}$ & $\begin{array}{c}\text { Produto da } \\
\text { atividade } \\
\text { pecuária }\end{array}$ & $\mathrm{R} \$ 0,20 / \mathrm{kg}$ & À vista & A tratar & $\begin{array}{c}\text { Zona Rural }- \\
\text { Dourados } / \mathrm{MS}\end{array}$ \\
2 & $\begin{array}{c}\text { Minhocas } \\
\text { Californianas }\end{array}$ & Iscas vivas & $\mathrm{R} \$ 0,35 /$ unidade & À vista & $\begin{array}{c}\text { Retirada } \\
\text { no local }\end{array}$ & Vila Sapé \\
3 & Big bags & $\begin{array}{c}\text { Produtores de } \\
\text { grãos }\end{array}$ & $\mathrm{R} \$ 3,00 /$ unidade & À vista & $\mathrm{A}$ tratar & $\begin{array}{c}\text { Zona Rural }- \\
\text { Dourados } / \mathrm{MS}\end{array}$ \\
\hline
\end{tabular}

Fonte: Pesquisa de mercado realizada no município de Dourados/MS e via site - https://www.mfrural.com.br

\section{Avaliação estratégica}

Para relatar as forças, oportunidades, fraquezas e ameaças da produção de húmus em Big bags foram utilizadas a teoria da matriz FOFA para realizar o levantamento dos dados relacionados à produção (Tabela 03).

Tabela 03. Dados da propriedade relacionados à Matriz FOFA. 
Pontos Fortes

\section{Pontos Fracos}

\begin{abstract}
Forças:
- Atividade sem necessidade mão de obra terceirizada;

- Flexibilidade na instalação e pode ser colocada ao ar livre, facilitando o manejo:

- Necessita de pouco tempo efetivo de trabalho;

- Ocupa pouco espaço físico;

- Atividade de custeio de baixo valor; e

- Multiplicação das minhocas, aumentando os números de indivíduos por Big bag, a cada ciclo.
\end{abstract}
Fraquezas:
- Necessita de que o produtor já tenha alguns equipamentos para processamento de matérias primas;
- Seja próximo a uma fonte de água potável;
- Necessita de matéria-prima de boa qualidade (vegetal e animal); e
- Necessita de um volume mínimo para estabilidade de produção, viabilidade econômica e capital de giro.

\section{Oportunidades:}

- Mercado com baixa concorrência na região;

- Parcerias com clientes (floriculturas, empresa de produção de mudas, produtores de hortifruti, empresas de jardinagem, entre outros);

- Alta demanda de produto em curtos períodos do ano;

- Venda das minhocas em períodos estratégicos do ano (calendário de pesca), aumentando a receita em períodos do ano de produção; e

- Informações de análise química contida no produto final.

\section{Ameaças:}

- Falta de divulgação/marketing do produto e seus benefícios; e

- Produtos sem padrão de qualidade porém, com menor valor de mercado, seja ele húmus ou terra vegetal.

Neste modelo de produção de húmus se faz necessário o uso de Big bags como meio de alocação das componentes do sistema. Os sistemas de produção de húmus convencionais, quando protegidos, tem como meio de alocação, os canteiros de alvenaria ou de bambu revestido com sombrite (EMBRAPA, CT 29).

Com relação a proteção contra predadores e/ou competidores, as Big bags é uma barreira física que contribui contra a evasão de minhocas do sistema e ajuda na conservação da água contida no material em produção, assim como, contribui com a drenagem e aeração durante o ciclo de produção do húmus e minimiza a contaminação com patógenos disseminados pelo ar (SOARES, 2019).

\section{Plano operacional}

\section{Descrição geral do processo operacional}

Para implantar o sistema, é necessária a utilização de Big bags com capacidade de carga no mínimo $1.000 \mathrm{~kg}$. Porém, não se deve preenchê-la totalmente para que não ocorra compactação do material e dificulte a infiltração/drenagem da água, além de proteger a superfície do material através da própria malha da Big bag.

A proporção aproximada do volume de material adicionado na Big bag foi a seguinte: material orgânico vegetal seco (folhas, restos de gramas e de culturas, entre outros) na proporção de $6,25 \%$ do volume da Big bag ou $20 \mathrm{~kg}$ e 78,13\% de material orgânico de origem animal curado (seja ele bovino, de caprino e/ou suíno sólidos) ou de 250 a $300 \mathrm{~kg}$. Somado a massa total, temos o volume de água inserido, para início do ciclo, de $15,62 \%$ ou aproximadamente $50 \mathrm{~L}$, isto dependendo da umidade em que o esterco curado se encontra.

Vale ressaltar que esses materiais de origem animal necessitam estar curtidos/curados para que quando incorporados ao material orgânico vegetal não tenham alta atividade fúngica. Outros organismos decompositores, que em suas atividades liberam calor, elevam a temperatura do material podendo causar a morte das minhocas. A temperatura ideal do processo de decomposição deve ficar em torno de $25^{\circ} \mathrm{C}$ (BRITO et al., 2010).

A alocação da Big bag deve ser realizada em um local de fácil acesso, para facilitar o manuseio tanto para manutenção da água durante o processo de produção quanto para a retirada do material no final do ciclo, para o beneficiamento. É desejável também, que o local seja sombreado e ventilado, a fim de garantir a eficiência de drenagem do excesso de água do composto e a aeração proporcionada pela malha da Big bag. 
A manutenção do sistema deve ser realizada semanalmente, com controle de umidade do material a ser produzido, ou seja, o húmus ficando em torno de $80 \%$ de umidade durante o ciclo, o que é ideal para o desenvolvimento das minhocas. Na montagem da Big bag, uma parte das folhas é colocada no fundo da bolsa, em seguida são inseridas camadas de material vegetal e animal. A incorporação das camadas pode facilitar a decomposição do material vegetal, assim acelerando o processo de decomposição por estarem similares às condições de um solo ideal para atividade de minhocas. Vale ressaltar que em períodos com condições amenas de temperatura, a mesma atividade fúngica incidente no material vegetal pode ajudar a manter a temperatura da massa maior do que a temperatura ambiente (BRITO et al., 2010).

Depois de adicionado todo o material dentro da Big bag inicia-se o processo de vermicompostagem. Insere-se a água até o momento em que for perceptível o início da drenagem na base inferior da Big bag. Essa água deve ser distribuída por toda a área superficial do material para que a infiltração ocorra de forma mais homogênea possível. Após acompanhamento da estabilização do material - aproximadamente uma semana as minhocas podem ser inseridas no processo.

Com a montante de minhocas sobre o material, sugere-se que seja feito uma depressão no centro para que as minhocas se aloquem dentro das Big bags espontaneamente. Após isso, a inserção da água deve ser realizada semanalmente, quantas vezes forem necessárias, para que o material mantenha de $75 \%$ a $80 \%$ o teor de água. O acompanhamento é feito de modo empírico, é importante ressaltar que o material não esteja nem seco, nem encharcado, podendo ser deformado quando pressionado com as mãos.

Este sistema pode ser conduzido ao ar livre (sob a sombra de árvores, com pequena inclinação do terreno para que haja drenagem do excesso de água ou escoamento da precipitação) para proporcionar um corredor de ar, que ao passar pela malha da Big bag, favoreça a aeração e ventilação da massa.

É importante manter sempre o teor de água presente no material para que não ocorra a evasão das minhocas do fundo da Big bag para o solo passando por entre a malha. Também deve haver cuidados em relação as formigas e outros indivíduos que possam vir a colocar em risco a produção.

Em aproximadamente 70 a 85 dias (dependendo das condições climáticas, do manejo e do próprio material) há a formação do húmus com aparência de "borra de café". A partir daí, o produto deve ser peneirado para garantir a padronização dos grânulos e retirada de impurezas e/ou materiais que não foram compostados. Posteriormente, o material deve ser armazenado em saco de rafia em local arejado por aproximadamente 30 dias para que a atividade microbiana diminua e estabilize (SCHIEDECK et al., 2006).

\section{Capacidade de instalação}

Após analisadas as questões de produção segura, é recomendável que se monte um sistema em módulos, onde um consiste em três unidades das Big bags com 250 a $300 \mathrm{~kg}$ de resíduo animal cada. Acerca do restante do volume da Big bag, uma parte é preenchida com material vegetal seco (em torno de $7 \%$ do volume útil da Big bag) e outra com água (aproximadamente 50L), dependendo da umidade já contida no esterco. Mesmo assim, ainda resta parte da Big bag sem ser preenchida, que servirá para cobrir o material e proteger a parte superior.

\section{Escalonamento de produção}

$\mathrm{Na}$ Tabela 04 é proposto o escalonamento do húmus de vermicompostagem em Big bags, durante o período de um ano de produção.

Tabela 04. Escalonamento de produção anual: $I=$ Início do ciclo de produção; $P$ = Processo de produção em andamento; F = Retirada do húmus pronto da Big bag; e X = Sem produção neste mês.

\begin{tabular}{|c|c|c|c|c|c|c|c|c|c|c|c|c|c|c|c|c|c|c|c|c|c|c|}
\hline \multirow{4}{*}{ Módulo 1} & \multirow{3}{*}{$\begin{array}{l} \\
\text { Big } \\
\text { bag } 1 \\
\text { Big } \\
\text { bag } 2\end{array}$} & \multirow{2}{*}{$\begin{array}{l}\text { Jan } \\
\end{array}$} & Fev & Mar & \multicolumn{2}{|c|}{ Abr } & \multicolumn{2}{|c|}{ Mai } & \multicolumn{2}{|c|}{ Jun } & \multicolumn{2}{|c|}{ Jul } & \multicolumn{2}{|c|}{ Ago } & \multicolumn{2}{|c|}{ Set } & \multicolumn{2}{|c|}{ Out } & \multicolumn{2}{|c|}{ Nov } & \multicolumn{2}{|c|}{ Dez } \\
\hline & & & $P$ & $P$ & $F$ & 1 & $P$ & & $P$ & & $F$ & 1 & $P$ & & $P$ & & $F$ & 1 & $P$ & & $P$ & \\
\hline & & $x$ & I & $P$ & $P$ & & $F$ & I & $P$ & & $P$ & & $F$ & 1 & $P$ & & $P$ & & $F$ & 1 & P & \\
\hline & $\begin{array}{l}\text { Big } \\
\text { bag } 3\end{array}$ & $x$ & $x$ & I & $P$ & & P & & $F$ & I & $P$ & & $P$ & & $\mathrm{~F}$ & I & $P$ & & $P$ & & $\mathrm{~F}$ & I \\
\hline
\end{tabular}


Módulo 2

\begin{tabular}{|c|c|c|c|c|c|c|c|c|c|c|c|c|c|c|c|c|c|c|c|c|c|}
\hline & Jan & Fev & Mar & $\mathbf{A b}$ & & $\mathrm{Ma}$ & & Jun & & Jul & & $\mathbf{A g}$ & & Set & & $\mathrm{Ou}$ & & No & & \multirow{2}{*}{\multicolumn{2}{|c|}{$\begin{array}{l}\text { Dez } \\
P\end{array}$}} \\
\hline $\begin{array}{l}\text { Big } \\
\text { bag } 4\end{array}$ & I & $P$ & $P$ & $F$ & I & $P$ & & $P$ & & $F$ & 1 & $P$ & & $\mathrm{P}$ & & $F$ & I & $P$ & & & \\
\hline $\begin{array}{l}\text { Big } \\
\text { bag } 5\end{array}$ & $X$ & I & $P$ & $P$ & & $F$ & I & $P$ & & $P$ & & $F$ & I & $P$ & & $P$ & & $F$ & I & $P$ & \\
\hline $\begin{array}{l}\text { Big } \\
\text { bag } 6\end{array}$ & $x$ & $x$ & I & $P$ & & $P$ & & $F$ & I & $P$ & & $P$ & & $F$ & I & $P$ & & $P$ & & $\mathrm{~F}$ & I \\
\hline
\end{tabular}

\section{Plano financeiro}

\section{Investimentos fixos}

Para estimar os custos iniciais da produção foram contabilizados como investimentos fixos os seguintes itens: óculos de proteção, luvas, regador, peneira $3 \#(\mathrm{~mm})$ e lona de polietileno $7 \times 5 \mathrm{~m}$ (Tabela 05).

Tabela 05. Investimento fixo para a instalação das Big bags para a produção de húmus por meio da vermicompostagem.

\begin{tabular}{llll}
\hline Descrição & Qtde & Valor Un. & Total \\
\hline Óculos de proteção & 1 & $\mathrm{R} \$ 5,00$ & $\mathrm{R} \$ 5,00$ \\
Luvas & 1 & $\mathrm{R} \$ 15,00$ & $\mathrm{R} \$ 15,00$ \\
Regador & 1 & $\mathrm{R} \$ 30,00$ & $\mathrm{R} \$ 30,00$ \\
Peneira 3\# & 1 & $\mathrm{R} \$ 35,00$ & $\mathrm{R} \$ 35,00$ \\
Lona Polietileno 7x5m & 1 & $\mathrm{R} \$ 110,00$ & $\mathrm{R} \$ 110,00$ \\
Total & & & $\mathbf{R} \$ \mathbf{1 9 5 , 0 0}$ \\
\hline
\end{tabular}

Além disso, foram contabilizados também os custos fixos operacionais mensais na Tabela 06 e depreciação na Tabela 07.

Tabela 06. Custos fixos mensais à produção de húmus por meio da vermicompostagem em Big bags.

\begin{tabular}{lc}
\hline Descrição & Valor \\
\hline Depreciação & $\mathrm{R} \$ 2,96$ \\
Pró-Labore & $\mathrm{R} \$ 261,25$ \\
SUBTOTAL & $\mathbf{R} \mathbf{2 6 4 , 2 1}$ \\
\hline
\end{tabular}

Tabela 07. Depreciação das máquinas e equipamentos a produção de húmus por meio da vermicompostagem em Big bags.

\begin{tabular}{lcccc}
\hline Ativos fixos & Valor do bem & $\begin{array}{c}\text { Vida útil em } \\
\text { anos }\end{array}$ & Depreciação anual & Depreciação mensal \\
\hline Equipamentos & $\mathrm{R} \$ 35,00$ & 10 & $\mathrm{R} \$ 3,50$ & $\mathrm{R} \$ 0,29$ \\
Utensílios & $\mathrm{R} \$ 160,00$ & 5 & $\mathrm{R} \$ 32,00$ & $\mathrm{R} \$ 2,67$ \\
TOTAL & & & $\mathrm{R} \$ 35,50$ & $\mathrm{R} \$ \mathbf{2 , 9 6}$ \\
\hline
\end{tabular}

Como capital de giro, simulou-se como estoque inicial a quantidade de esterco bovino $1.500 \mathrm{~kg}$, sendo o valor unitário de $\mathrm{R} \$ 0,20$ aquisição de minhocas vermelhas californianas, aproximadamente $3 \mathrm{~L}$ que equivale a $\mathrm{R} \$ 327,00 \mathrm{~L}^{-1}$ e o material orgânico na quantidade de $120 \mathrm{~kg}$ (obtido na propriedade), obteve-se com estoque inicial o valor de $\mathrm{R} \$ 1.280,00$ - A para iniciar o investimento. O preço incidente sobre o esterco tem por finalidade, apresentar um cenário em que o material animal utilizado é resíduo de outro sistema produtivo bovinocultura de leite ou corte - que passa a ser fornecedor desta matéria-prima para a produção de húmus de minhoca. No entanto há a possibilidade de que essa matéria-prima possa ser da propriedade, se houver produção animal. O caixa mínimo para o primeiro mês está apresentado na Tabela 08. 
Tabela 08. Caixa mínimo com base em 30 dias para o capital de giro do primeiro ciclo de produção de húmus por meio da vermicompostagem em Big bags.

\begin{aligned} & \hline Descrição Valor \\ & \hline 1. Custo fixo mensal $\mathrm{R} \$ 264,21 \\ &$ 2. Custo variável mensal $\mathrm{R} \$ 168,35 \\ &$ 3. Custo total $\mathrm{R} \$ \mathbf{4 3 2 , 5 6} \\ &$ Total Caixa Mínimo - B $\mathbf{R} \mathbf{4 3 2 , 5 6} \\ &$\hline\end{aligned}

\section{Resultados}

Conforme pode ser verificado na Tabela 09, o resultado do capital de giro necessário para a produção de $960 \mathrm{~kg}$ de húmus em seis Big bags é de $\mathrm{R} \$ 1.712,56$ para o planejamento presente.

Tabela 09. Capital de giro necessário para iniciar a produção de húmus por meio da vermicompostagem em Big bags.

\begin{tabular}{|c|c|c|}
\hline Descrição & \multicolumn{2}{|c|}{ Valor } \\
\hline Estoque inicial $-\mathrm{A}$ & \multicolumn{2}{|c|}{$\mathrm{R} \$ 1.280,00$} \\
\hline Caixa mínimo - B & \multicolumn{2}{|c|}{$\mathrm{R} \$ 432,56$} \\
\hline Total(C) Capital de giro & \multicolumn{2}{|c|}{$R \$ 1.712,56$} \\
\hline \multicolumn{3}{|c|}{$\begin{array}{l}\text { O investimento inicial está apresentado na Tabela } 10 \text { simulado a partir de dados de investimentos fixo } \\
\text { e capital de giro. O faturamento mensal necessário para produzir o húmus em Big bags estão apresentados na } \\
\text { Tabela 11. Os demonstrativos de resultados (DRE) estão apresentados na Tabela } 12 \text {. }\end{array}$} \\
\hline Descrição dos investimentos & Valor & $(\%)$ \\
\hline Investimentos fixos (1) & $\mathrm{R} \$ 195,00$ & 10,22 \\
\hline Capital de giro (2) & $R \$ 1.712,56$ & 89,78 \\
\hline TOTAL $(1+2)$ & $R \$ 1.907,56$ & 100,00 \\
\hline
\end{tabular}

Tabela 11. Faturamento mensal para iniciar a produção de húmus por meio da vermicompostagem em Big bags. A unidade (Un) para Húmus é expressa em kg e para Minhocas é expressa em quantidade de indivíduos.

\begin{tabular}{|c|c|c|c|c|}
\hline $\mathbf{N}^{\circ}$ & Produto & Quantidade prevista para venda (Unt) & Preço unitário de venda & Faturamento total \\
\hline 1 & Húmus & 160 & $\mathrm{R} \$ 3,00 / \mathrm{kg}$ & $\mathrm{R} \$ 960,00$ \\
\hline 2 & Minhocas & 400 & $\mathrm{R} \$ 0,35$ /unidade & $\mathrm{R} \$ 140,00$ \\
\hline \multicolumn{4}{|c|}{ TOTAL } & $R \$ 1.100,00$ \\
\hline
\end{tabular}

Tabela 12. Demonstração de resultado operacional para iniciar a produção de húmus por meio da vermicompostagem em Big bags. A Margem de contribuição é o resultado da receita após subtrair os custos e/ou despesas variáveis, que exerce influência direta na lucratividade do negócio.
Descrição
Valor
(\%)

1. Receita total vendas (1)

$R \$ 1.100,00$

100,00

2. Custos variáveis totais (2) 
$2.1 \quad(-)$ Custos com materiais diretos MV

3. Margem de contribuição (3)

4. Custos fixos totais (4)

5. Resultado operacional (3-4)
$\mathrm{R} \$ 168,35$

15,30

$\mathrm{R} \$ 931,65$

84,70

$\mathrm{R} \$ 264,21 \quad 24,02$

$\mathrm{R} \$ 264,21 \quad 24,02$

$\mathbf{R} \$ 667,44$

60,68

\section{Discussão}

A simulação de produção de húmus por meio da técnica de vermicompostagem em Big bags atende aos preceitos solicitados de segurança e reutilização de resíduos sólidos, previstos na Lei $n^{\circ}$ 12.305/2010 (BRASIL, 2010).

O plano de negócios descrito como um sistema de produção de adubos orgânicos a partir de húmus de minhoca mostrou-se promissor. Nesse sistema, cada módulo possuía três Big bags com aproximadamente 320 $\mathrm{kg}$ cada. Ao final do ciclo de vermicompostagem foi beneficiado em torno de $160 \mathrm{~kg}$ de húmus pronto para uso comercial.

Tabela 13. Indicadores de viabilidade, via software CEPN 3.0, apresenta informações financeiras para a empresa como: ponto de equilíbrio, lucratividade, rentabilidade e payback (prazo de retorno do investimento).

\begin{tabular}{lc}
\hline \multicolumn{1}{c}{ Indicadores } & Ano $\mathbf{1}$ \\
\hline Ponto de Equilíbrio & $\mathrm{R} \$ 3.743,44$ \\
Lucratividade & $60,68 \%$ \\
Rentabilidade & $419,87 \%$ \\
Valor Presente Líquido (VPL) & $\mathrm{R} \$ 1.391,78$ \\
Retorno sobre Investimento (ROI) & $154,3 \%$ \\
Prazo de retorno do investimento - Payback & 3 meses \\
\hline
\end{tabular}

Planejou-se um sistema com dois módulos de produção, seis Big bags, que geraram o lucro de $\mathrm{R} \$ 667,44 / \mathrm{mês}$, a partir do terceiro mês de produção. Com uma produção padronizada, desde o período de cura do resíduo animal, até a montagem das Big bags e inserção das minhocas, a partir do quinto mês foi produzido $160 \mathrm{~kg} / \mathrm{mês}$ de húmus, seguindo a Tabela do escalonamento da produção (Tabelas 4 e 12).

A partir de outros indicadores financeiros, para estimar possíveis cenários futuros e/ou averiguar resultados de operações já concluídas, foram realizadas análises através de Taxa Interna de Retorno (TIR), Valor Presente Líquido (VPL) e Retorno sobre Investimento (ROI), onde todas apresentam valores favoráveis a atividade econômica do negócio (Tabela 13). A TIR e obteve resultado de $25 \%$ e VPL foram calculados com o tempo em meses, para o período de 12 meses. Para o ROI foram utilizados valores presentes na Tabela 12 para a execução dos cálculos, onde apresentou resultado de 154,3\%, que significa um retorno de uma vez e meia dos custos totais.

A partir desses resultados, será possível sugerir ao produtor que faça uma análise prévia em sua propriedade para verificar a viabilidade de adoção do sistema, ou seja, se há oferta de resíduos na mesma, além de recursos hídricos e sombra (SCHIEDECK et al., 2006).

O planejamento é importante pois, permite ao produtor rural escolher os indicadores que mostre a oportunidade, ou não, de utilizar tal sistema de produção como atividade secundária ou até primária na propriedade. É importante também ter parcerias com fornecedores e consumidores com fluxo de demanda continua de húmus, para que se tenha uma projeção de produção e de receita dando mais credibilidade ao planejamento e diminuindo riscos na comercialização (BULEGON et al., 2012).

Essas medidas reduzem os custos de investimento com matéria-prima, sendo o custo maior com a aquisição das minhocas, fator importante no processo de produção do húmus. Por conseguinte, a montagem e o escalonamento de produção devem ser feitos juntamente com o planejamento operacional (Tabela 04). 
Para o produtor rural, esta pode ser uma nova alternativa de renda, por sua praticidade de manejo, facilidade no controle de todas as etapas de produção, visto que o uso de adubos orgânicos apresenta demanda crescente devido à reposição de nutrientes por meio da ciclagem a um custo menor que os fertilizantes químicos (LOSS et al., 2009; LOSS et al., 2015; SCHIEDECK et al., 2006; BULEGON et al., 2012).

\section{Conclusão}

Os indicadores financeiros (ROI, TIR e VPL) foram favoráveis para discriminar a lucratividade de 60,68\% que equivale à $\mathrm{R} \$ 667,44 / \mathrm{mês}$, onde o retorno do investimento inicial se conclui ao terceiro mês para este modelo.

A produção de adubos orgânicos por meio da técnica de vermicompostagem utilizando-se Big bags é uma técnica economicamente viável ao produtor rural e ambientalmente correta.

Além de ser uma nova alternativa de renda aos produtores, essa técnica pode auxiliar na redução dos impactos ambientais causados pelo descarte incorreto dos resíduos orgânicos gerados em propriedades rurais.

\section{Agradecimentos}

Ao curso técnico em Agronegócio-Senar/MS e a Universidade Federal da Grande Dourados pelo apoio institucional.

\section{Referências}

BASSACO, A.C., ANTONIOLLI, Z.I., BRUM JÚNIOR, B.S., ECKHARDT, D.P., MONTAGNER, D.F., BASSACO, G.P. Caracterização química de resíduos de origem animal e comportamento de Eisenia andrei. Ciência e Natura, 37, 45-51. 2015. https://doi.org/10.5902/2179460X1324

BLOUIN, M., BARRERE, J., MEYER, N., LARTIGUE, S., BAROT, S., MATHIEU, J. Vermicompost significantly affects plant growth. A meta-analysis. Agronomy for Sustainable Development, 39, 34. 2019. https://doi.org/10.1007/s13593-019-0579-x

BRASIL. MINISTÉRIO DE MEIO AMBIENTE - MMA. Compostagem doméstica, comunitária e institucional de resíduos orgânicos: manual de orientação/Ministério do Meio Ambiente, Centro de Estudos e Promoção da Agricultura de Grupo, Serviço Social do Comércio. -- Brasília, DF, P.9-63. MMA, 2017. Disponível em: https://www.mma.gov.br/images/arquivo/80058/Compostagem-

ManualOrientacao MMA 2017-06-20.pdf. Acesso em: 02 fev 2020.

BRASIL. Institui a Política Nacional de Resíduos Sólidos; altera a Lei $\mathbf{n}^{\mathbf{0}} \mathbf{9 . 6 0 5}$, de 12 de fevereiro de 1998. (Lei $n^{\circ} 12.305$, de 2 de agosto de 2010). Diário Oficial da República Federativa do Brasil, 2010. Disponível em: http://www.planalto.gov.br/ccivil 03/ ato2007-2010/2010/lei/l12305.htm. Acesso em: 02 fev 2020.

BRITO, F.S., MILLER, P.R.M., STADNIK, M. Presença de Trichoderma spp em composto e suas características para o controle de fitopatógenos. Revista Brasileira de Agroecologia, 5, 43-53. 2010. ISSN 1980-9735. Disponível em: <http://revistas.abaagroecologia.org.br/index.php/rbagroecologia/article/view/7683>.

BULEGON, L.G., CASTAGNARA, D.D., ZOZ, T., OLIVEIRA, P.S.R., SOUZA, F.H. Análise econômica na cultura do milho utilizando adubação orgânica em substituição a mineral. Ensaios e Ciência: Ciências Biológicas, Agrárias e da Saúde. 16, 81-91. 2012. ISSN:1415-6938.

CONTEFLEX. O que são Big Bags? Conheça as vantagens das embalagens flexíveis!. 2018. Disponível em:http://blog.conteflex.com.br/o-que-sao-bigbagss-conheca-as-vantagens-das-embalagens-flexiveis/ Acesso em: 20/01/2020. 
CONTI, S., VILLARI, G., FAUGNO, S., MELCHIONNA J., SOMMA, S., CARUSO, G. Effects of organic vs. conventional farming system on yield and quality of strawberry grown as an annual or biennial crop in southern Italy. Scientia Horticulturae, 180, 63-71. 2014. https://doi.org/10.1016/j.scienta.2014.10.015

DAL BOSCO, T.C., GONÇALVES, F., ANDRADE, F.C., TAIATELE JUNIOR, I., SILVA, J.S., SBIZZARO, M., Contextualização teórica: compostagem e vermicompostagem, In Compostagem e

vermicompostagem de resíduos sólidos: resultados de pesquisas acadêmicas. São Paulo: Blucher, 2017. p. 19-44.

GLIESSMAN, S.R. Agroecologia: Processos ecológicos em agricultura sustentável. Porto Alegre, Universidade Federal do Rio Grande do Sul. 2000. 653p.

MEDEIROS, P.R.F., DUARTE, S.N., DIAS, C.T.S. Tolerância da cultura do pepino a salinidade em ambiente protegido. Revista Brasileira Engenharia Agrícola Ambiental, 13, 406-410. 2009.

https://doi.org/10.1590/S1415-43662009000400006

LOSS, A., BASSO, A.; OLIVEIRA, B.S., KOUCHER, L.P., OLIVEIRA, R.A., KURTZ, C., LOVATO, P.E., CURMI, P., BRUNETTO, G., COMIN, J.J. Carbono orgânico total e agregação do solo em sistema de plantio direto agroecológico e convencional de cebola. Revista Brasileira de Ciência do Solo, 39, $1212-$ 1224. 2015. https://doi.org/10.1590/01000683rbcs20140718

LOSS, A., PEREIRA, M.G., SCHULTZ, N., ANJOS, L.H.C., SILVA, E.M.R. Atributos químicos e físicos de um Argissolo Vermelho-Amarelo em sistema integrado de produção agroecológica. Pesquisa agropecuária Brasileira, 44, 68-75. 2009. https://doi.org/10.1590/S0100-204X2009000100010

SANTOS, D.G., DINIZ, B.L. M.T., DINIZ NETO, M.A., SILVA, J.H.C.S., OLIVEIRA FILHO, W.N., FERREIRA FILHO, R.M. Growth and chlorophyll in noni seedlings irrigated with saline water in substrate with vermicompost. Revista Brasileira de Engenharia Agrícola e Ambiental, 23, 586-590. 2019.

https://doi.org/10.1590/1807-1929/agriambi.v23n8p586-590

SCHIEDECK, G., GONÇALVES, M.M., SCHWENGBER, J.E. Minhocultura e produção de húmus para a agricultura familiar. Embrapa Clima Temperado-Circular Técnica (INFOTECA-E). 2006.

SMYTH, A.J., DUMANSKI, J.A. Framework for evaluating sustainable land management. Canadian Journal of Soil Science,75, 401-406. 1995. Disponível em: http://www.fao.org/land-water/land/landgovernance/land-resources-planning-toolbox/category/details/en/c/1029518/.

SOARES, A.M. Produção de húmus em sistema big bags: proposição de um modelo de negócio para o produtor rural. Trabalho de conclusão de curso. 25f. Técnico em Agronegócio, do Serviço Nacional de Aprendizagem Rural - SENAR da Regional de Mato Grosso do Sul. 2019. 